\title{
Diversity in long-term synaptic plasticity at inhibitory synapses of striatal spiny neurons
}

\author{
Pavel E. Rueda-Orozco, Ernesto Mendoza, Ricardo Hernandez, Jose J. Aceves, \\ Osvaldo Ibanez-Sandoval, Elvira Galarraga and Jose Bargas ${ }^{1}$ \\ Departamento de Biofísica, Instituto de Fisiologia Celular-Neurociencias, Universidad Nacional Autonoma de México (UNAM), \\ México City, Distrito Federal, Mexico 04510
}

\begin{abstract}
Procedural memories and habits are posited to be stored in the basal ganglia, whose intrinsic circuitries possess important inhibitory connections arising from striatal spiny neurons. However, no information about long-term plasticity at these synapses is available. Therefore, this work describes a novel postsynaptically dependent long-term potentiation (LTP) at synapses among spiny neurons (intrinsic striatal circuitry); a postsynaptically dependent long-term depression (LTD) at synapses between spiny and pallidal neurons (indirect pathway); and a presynaptically dependent LTP at strionigral synapses (direct pathway). Interestingly, long-term synaptic plasticity differs at these synapses. The functional consequences of these long-term plasticity variations during learning of procedural memories are discussed.
\end{abstract}

[Supplemental material is available online at www.learnmem.org.]

Long-term synaptic plasticity has been proposed as a mechanism for information storage and has been described at both excitatory and inhibitory synapses in several areas of the brain and under different stimulation paradigms (e.g., Bliss and Lomo 1973; Racine et al. 1983; Calabresi et al. 1992a,b; Dudek and Bear 1992; CastroAlamancos et al. 1995; Wang and Gean 1999; Martin et al. 2000; Malenka and Bear 2004; Mendoza et al. 2006; Sjostrom et al. 2008). Because the basal ganglia are involved in procedural learning (Cools 1984; Graybiel 2008), great efforts in describing synaptic plasticity in these structures have been performed. However, most studies have been focused on excitatory corticostriatal synapses, where both long-term potentiation and depression (LTP and LTD, respectively) have been observed (Calabresi et al. 1992a,b; Lovinger et al. 1993; Charpier and Deniau 1997; Shen et al. 2008). On the other hand, scarce efforts have been dedicated to elucidate long-term synaptic plasticity at striatal inhibitory synapses (Adermark et al. 2009), which are a main component of the internal circuitry and the output of the neostriatum. Medium spiny neurons (MSNs) are the GABAergic projection neurons of the neostriatum, and their synaptic contacts include three main output pathways and targets. Here, we ask if some type of long-term synaptic plasticity can be induced at these synapses. The three main targets of MSNs studied here are: other MSNs innervated by intrinsic axon collaterals, substantia nigra reticulata $(\mathrm{SNr})$ projection neurons innervated by the "direct" strionigral pathway, and globus pallidus (GP) neurons innervated by the "indirect" striopallidal pathway (Alexander et al. 1986; Albin et al. 1989). We employed the widely used high frequency stimulation (HFS) paradigm to begin exploring long-term synaptic plasticity at these different synapses (e.g., Mendoza et al. 2006), which possess presynaptic nerve endings originating from MSNs. Interestingly, using the same stimulation protocol, we disclosed three different classes of long-term synaptic plasticity, one for each of these synapses.

The experiments were performed on brain slices $(300 \mu \mathrm{m}$ thick) obtained from Wistar rats (PD14-40). Animals were anes-

\footnotetext{
'Corresponding author.
}

Email jbargas@ifc.unam.mx; fax 5255-5622-5747.

Article is online at http://www.learnmem.org/cgi/doi/10.1101//m.1439909. thetized, intracardially perfused, and decapitated. Each brain was quickly removed and cut using a vibratome (Ted Pella) immersed in a $4^{\circ} \mathrm{C}$ solution with the following composition (in $\mathrm{mM}$ ): 126 choline-Cl, $2.5 \mathrm{KCl}, 1 \mathrm{MgCl}_{2}, 2 \mathrm{CaCl}_{2}, 26 \mathrm{NaHCO}_{3}, 10$ glucose $\left(\mathrm{pH}=7.4\right.$, saturated with $95 \% \mathrm{O}_{2}$ and $\left.5 \% \mathrm{CO}_{2}, 298 \mathrm{mOsm} / \mathrm{l}\right)$. Slices were transferred to a saline solution containing (in $\mathrm{mM}$ ): 123 $\mathrm{NaCl}, 2.5 \mathrm{KCl}, 1.3 \mathrm{MgCl}_{2}, 2.4 \mathrm{CaCl}_{2}, 26 \mathrm{NaHCO}_{3}, 1.2 \mathrm{NaH}_{2} \mathrm{PO}_{4}, 10$ glucose $\left(\mathrm{pH}=7.4,25^{\circ} \mathrm{C}-27^{\circ} \mathrm{C}\right.$ saturated with $95 \% \mathrm{O}_{2}$ and $5 \% \mathrm{CO}_{2}$, $298 \mathrm{mOsm} / \mathrm{l})$. The slices were left for equilibration in the oxygenated saline at room temperature for $>1 \mathrm{~h}$. After equilibration, single slices were transferred to a recording chamber and superfused continuously with oxygenated saline $(4-5 \mathrm{~mL} / \mathrm{min})$. Wholecell recordings were performed using infrared differential interference contrast microscopy with an upright microscope and a digital camera. Inhibitory postsynaptic currents (IPSCs) were recorded with the help of an amplifier (Dagan Corp.). Series resistance ranged from 5 to $20 \mathrm{M} \Omega$ and was commonly compensated $\sim 80 \%$. In addition, input and access resistance were continuously monitored during the experiment by evoking transmembrane current with a voltage command (Figs. 1B, 2B, and 3B, see below). Changes in synaptic currents after potentiation/depression occurred without changes in this current. Experiments were discontinued if changes of $\sim 20 \%$ in this measurement were observed.

Data acquisition was performed with an AT-MIO-16E4 board (National Instruments) and software designed in the LabView environment (Lemus-Aguilar et al. 2006). Patch micropipettes (2$6 \mathrm{M} \Omega$ ) were pulled (Sutter Instrument) from borosilicate glass tubes (1.5 mm OD, WPI) and were filled with internal saline containing (in mM): $72 \mathrm{KH}_{2} \mathrm{PO}_{4}, 36 \mathrm{KCl}, 1.1$ EGTA, 10 HEPES, 2 $\mathrm{CaCl}_{2}, 1 \mathrm{MgCl}_{2}, 2$ ATP-Mg, 0.3 GTP-Na, 5 QX-314 (pH 7.3 and 272-275 mOsM/l). High chloride internal solution was used to obtain IPSCs as inward currents at a holding potential of $-80 \mathrm{mV}$. IPSCs were evoked with field stimulation via sharp (pencil-shaped) concentric bipolar electrodes $(12 \mu \mathrm{m}$ at the tip; $10 \mathrm{k} \Omega$; FHC) attached to an isolation unit (Digimiter). Stimulation electrodes were positioned either at the GP, the neostriatum (NSt), or internal capsule near the $\mathrm{SNr}$ in sagittal brain slices. Distances between the recording and stimulation electrodes were $0.5-1.0 \mathrm{~mm}$ in all configurations. All recordings were done in the presence of the $\alpha$-amino-3-hydroxyl-5-methyl-4-isoxazolepropionate/kainate 
receptor (AMPA/KA) selective antagonist 6-cyano-2,3-dihydroxy7-nitro-quinoxaline disodium salt (CNQX; $10 \mu \mathrm{M})$ and the $\mathrm{N}$-methyl-D-aspartate (NMDA) antagonist (2R)-amino-5-phosphonovaleric acid (AP5; $50 \mu \mathrm{M})$. Drugs were stored in stock solutions to be dissolved in their final concentrations into the superfusion saline.

To obtain baseline paired IPSCs, two shocks with a 50-msec interpulse interval were delivered at a rate of $0.1 \mathrm{~Hz}$. Stimulation parameters were adjusted to obtain currents of 100-500 pA during the control. The paired pulse ratio (PPR) was expressed as the amplitude ratio IPSC2/IPSC1. To induce synaptic plasticity, a high frequency stimulation (HFS) paradigm was used: Two trains of 100 $\mathrm{Hz}$ ( 1 sec each, total of 200 stimuli) were delivered with an intertrain interval of $10 \mathrm{sec}$ (Mendoza et al. 2006). Long-term plasticity was considered if a significant and sustained increase/ decrease in IPSC mean amplitude lasted $>20 \mathrm{~min}$. The freedistribution Wilcoxon's $t$-test was used to compare baseline IPSCs amplitudes and PPR at $t=0-5$ min with IPSC amplitudes and PPR at $t=30-35 \mathrm{~min}$ in the same experiment; as seen in the time courses, 0.05 was used as significance level.

Figure 1A illustrates the experimental configuration to obtain IPSCs from axon collaterals that innervate MSNs: Field stimulation was delivered at the GP to antidromically activate striofugal projections passing trough the GP (Guzmán et al. 2003; PerezRosello et al. 2005; Salgado et al. 2005; Tecuapetla et al. 2005). IPSCs were evoked in the presence of CNQX and DL-2-amino-5phosphonopentanoic acid (APV). Figure $1 \mathrm{~B}$ shows IPSC traces from a representative neuron in control conditions and after the high frequency stimulation (HFS) paradigm (see above). Normalization and superimposition of these traces shows that persistent changes in IPSCs amplitude occur without consistent changes in the paired pulse ratio (PPR). Figure 1C shows the time course of a representative experiment, and Figure 1D shows normalized amplitude changes averaged from a sample of neurons exhibiting plasticity: After a brief period with post-tetanic potentiation, HFS enhanced IPSC amplitude (Fig. 1E) for at least $20 \mathrm{~min}$ (LTP) in 34\% of tested neurons ( $n=6$ are the positive cases; $P<0.04$ ). The remaining cases did not show any change after HFS (data not shown).

Because PPR did not reveal a consistent or significant change, our preliminary working hypothesis is that this type of LTP is mediated, mainly, postsynaptically (Fig. 1F). Note that this plasticity is not dependent on NMDA, although further experiments are needed to assess the participation of this transmitter agonist.

Figure $2 \mathrm{~A}$ illustrates the experimental configuration to obtain IPSCs from the striopallidal or indirect pathway that innervates neurons in the GP: Field stimulation was delivered at the neostriatum (NSt) to orthodromically activate striatal projections to the GP (Cooper and Stanford 2001; Shin et al. 2003; Engler et al. 2006; Sims et al. 2008). IPSCs were evoked in the presence of $\mathrm{CNQX}$ and APV. Figure 2B shows IPSCs traces from a representative neuron in control conditions and after HFS. Normalization and superimposition of these traces shows that changes in IPSCs amplitude occur without consistent changes in the PPR. Figure $2 \mathrm{C}$ shows the time course of a representative experiment, and Figure 2D shows normalized amplitude changes in a sample of neurons: HFS decreased IPSC amplitude (Fig. 2E) for at least $20 \mathrm{~min}$ (LTD) in all tested neurons $(n=8 ; P<0.03)$. Because PPR did not reveal a consistent or significant change, it is suggested that LTD is mediated, mainly, postsynaptically (Fig. 2F). Again, further studies are needed to clarify possible NMDA participation and the nature of the NMDA-independent plasticity.

Figure 3A illustrates the experimental configuration to obtain IPSCs from the strionigral or direct pathway that innervates neurons in the SNr: Field stimulation was delivered at the internal capsule in a sagittal slice including the NSt to orthodromically activate striatal projections to the SNr (Radnikow and Misgeld
A
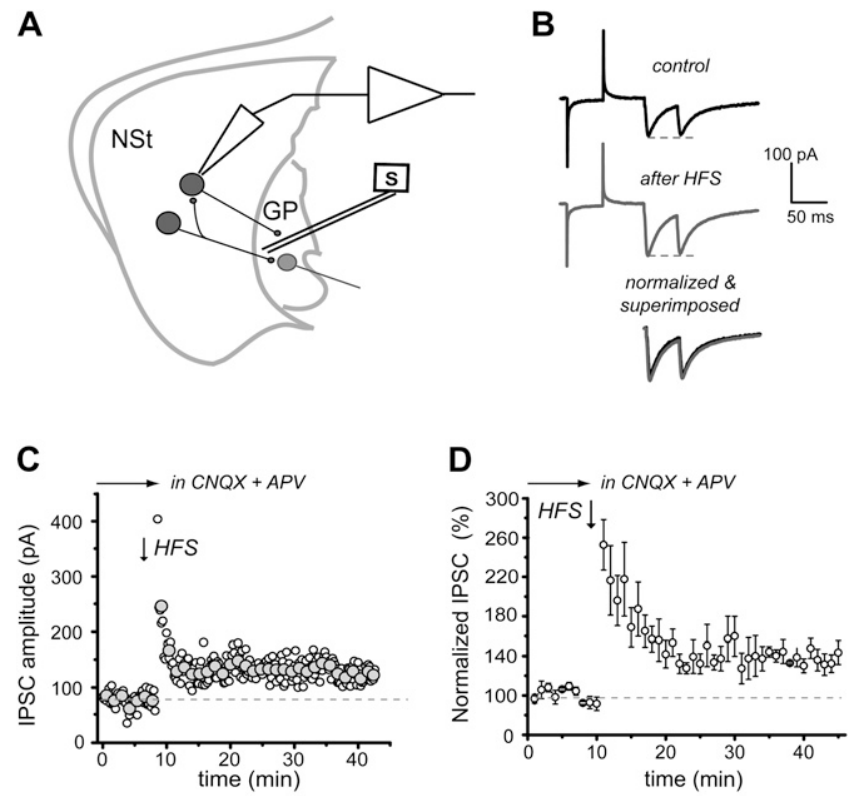

E

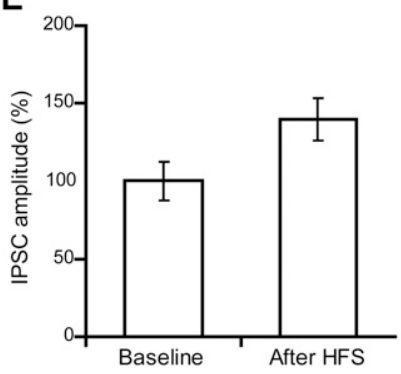

$\mathbf{F}$

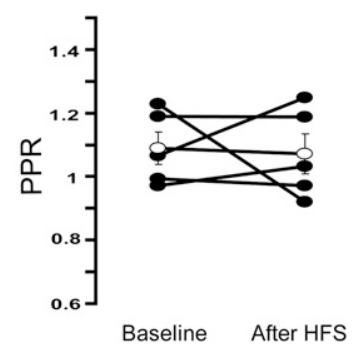

Figure 1. Long-term potentiation induced at connections between medium spiny neurons. $(A)$ Experimental configuration: (NSt) neostriatum, (GP) globus pallidus, ( $S$ ) stimulus electrode. (B) Representative evoked pairs of IPSCs during baseline and after high frequency stimulation (HFS). Amplitude normalization and superimposition shows no change in the paired pulse ratio (PPR). (C) Time course of LTP induction (same cell as in $B$ ). (Open circles) Individual responses, (filled gray circles) averages of 10 individual responses. $(D)$ Amplitude normalization and average of six positive experiments similar to that in $B, C$. $(E)$ Histogram illustrating normalized IPSCs amplitudes before and after HFS $(P<0.04 ; n=6)$. $(F)$ Inconsistent PPR changes in the cell sample. (Filled circles) Individual experiments, (open circles) mean of individual experiments.

1998; Beurrier et al. 2006; Misgeld et al. 2007). IPSCs were evoked in the presence of CNQX and APV. Figure 3B shows IPSCs traces from a representative neuron in control conditions and after HFS. Normalization and superimposition of these traces shows that changes in IPSCs amplitude occur with a consistent and significant change in the PPR: In fact, paired pulse facilitation (PPF) became paired pulse depression (PPD) after HFS. Figure 3C shows the time course of a representative experiment, and Figure 3D shows normalized amplitude changes in a sample of neurons: HFS increased the amplitude of the first IPSC by $250 \%$ as compared with baseline conditions (Fig. 3E; $n=8 ; P<0.001$ ). This increase was maintained for at least $20 \mathrm{~min}$ (LTP) in all tested neurons. Because PPR changed in a consistent and significant way $(n=8 ; P<$ $0.03)$, it is our working hypothesis that this type of LTP is mediated, mainly, presynaptically (Fig. 1F; see Supplemental Fig. 1). Further studies are needed to clarify possible NMDA participation and the signaling involved in this plasticity. 
A
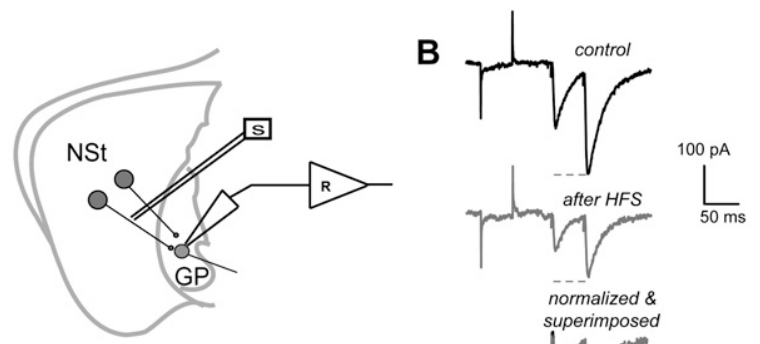

C $\longrightarrow$ in $C N Q X+A P V$

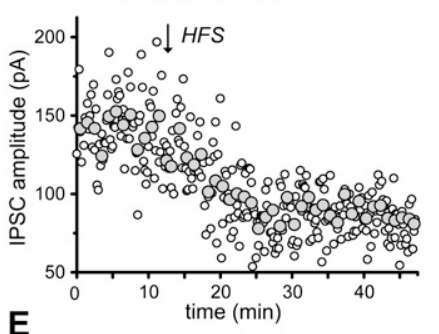

E
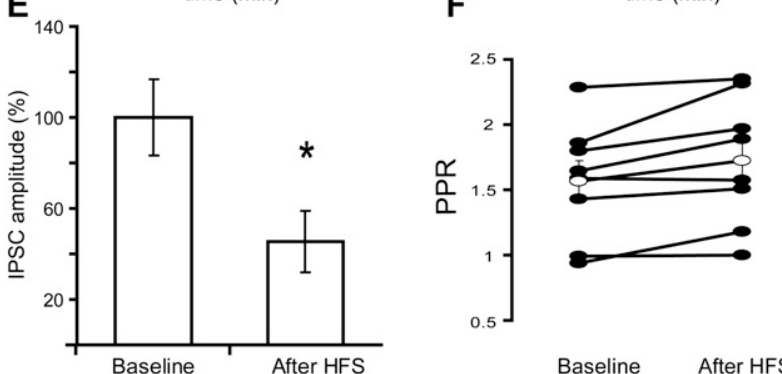

Baseline After HFS

Figure 2. Long-term depression induced at striopallidal "indirect" connections. (A) Experimental configuration: ( $\mathrm{S}$ ) stimulus electrode, (R) recording. (B) Representative evoked pairs of IPSCs during baseline and after HFS. Amplitude normalization and superimposition shows no change in PPR. (C) Time course of LTD induction (same cell as in B). (Open circles) Individual responses, (filled gray circles) averages of 10 individual responses. $(D)$ Amplitude normalization and average of eight experiments similar to that in $B, C$. (E) Histogram illustrating normalized IPSCs amplitudes before and after HFS $\left({ }^{*} P<0.03 ; n=8\right)$. $(F)$ Nonsignificant PPR changes in the cell sample. (Filled circles) Individual experiments, (open circles) mean of individual experiments.

The basal ganglia and, specifically, the NSt, are storage locations for procedural memories, motor routines, and habits (Cools 1984; Graybiel 2008). Thus, long-term synaptic plasticity has been studied at corticostriatal synapses, the almost exclusive focus of plasticity studies at the basal ganglia. However, possible long-term plastic changes at inhibitory synapses should not be dismissed (Adermark et al. 2009). They may be important because cycles of correlated activity similar to memory traces have been recorded in vivo and in vitro even in decorticated preparations (Carrillo-Reid et al. 2008, 2009; Yin et al. 2009), and the role of inhibitory synapses in the genesis of these events appears to be important (Flores-Barrera et al. 2009). Thus, the main finding of the present study is that long-term synaptic plasticity is an important property of inhibitory synapses arising from MSNs connections. Long-term synaptic plasticity at inhibitory synapses (Sjostrom et al. 2008) has been shown in the hippocampus (Chevaleyre and Castillo 2003; Mendoza et al. 2006), cerebellum (Kano 1995), and NSt itself (Adermark et al. 2009). We used the same HFS paradigm for an initial comparative exploration of longterm synaptic plasticity at inhibitory synapses (e.g., Mendoza et al. 2006) originating from MSNs. The plasticity at their different targets came out to be heterogeneous.
This suggests that the postsynaptic side is a main regulator on deciding the type of plasticity. In fact, LTP and LTD were observed at spiny-spiny and spiny-pallidal connections, respectively, with no consistent or significant changes in the PPR. Therefore, the most parsimonious interpretation of these results is that different postsynaptic signaling mechanisms are responsible for long-term plasticity at each of these sites, since the postsynaptic target is different. Interestingly, not all spiny to spiny connections exhibited long-term plasticity. Because we antidromically stimulate striofugal fibers passing through the GP, which include those that have presynaptic $D_{1}$-class and presynaptic $D_{2}$-class receptors (Guzmán et al. 2003; Salgado et al. 2005; Tecuapetla et al. 2007), it is probable that only one class of MSN, direct or indirect, exhibits LTP, given the reported functional differences in their mutual connections (Taverna et al. 2008). Nevertheless, and because NMDA-antagonists were used in this initial exploration to rule out plasticity propagation from corticostriatal connections, it perhaps may be expected that NMDA could become an important
A

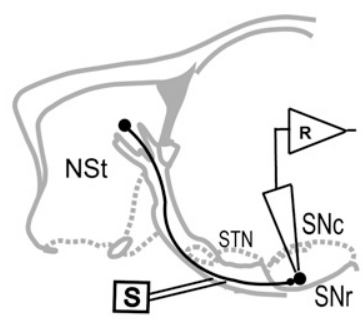

C

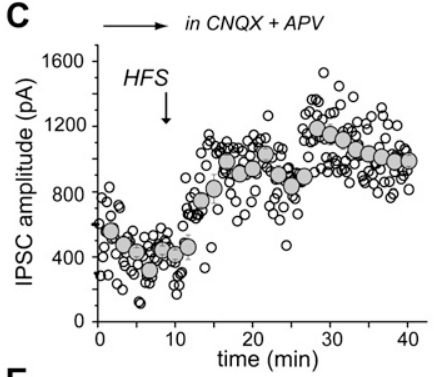

E

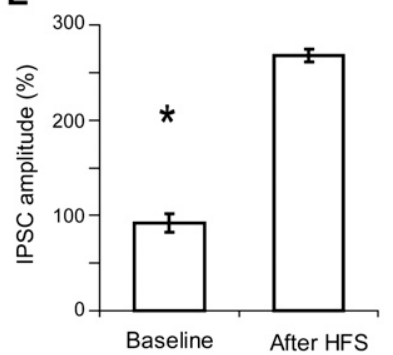

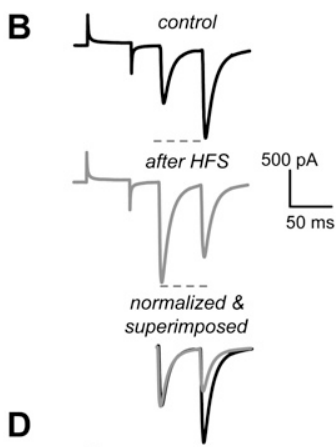

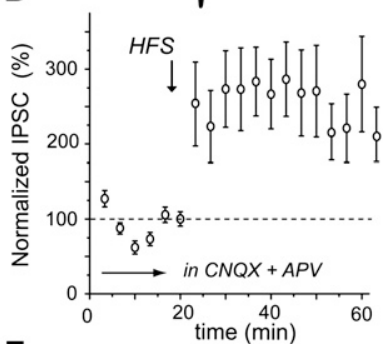

$\mathbf{F}$

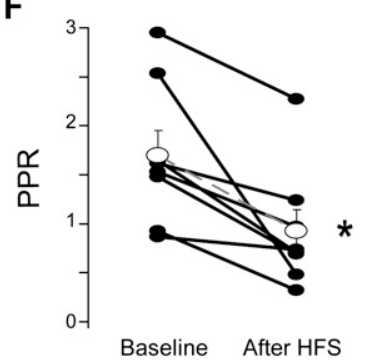

Figure 3. Long-term potentiation induced at strionigral "direct" connections. (A) Experimental configuration: (NSt) neostriatum, (STN) subtallamic nucleus, (SNc) subtantia nigra compacta, $(\mathrm{SNr})$ subtantia nigra reticulata, $(S)$ stimulus electrode, $(\mathrm{R})$ recording. (B) Representative evoked pairs of IPSCs during baseline and after HFS. Amplitude normalization and superimposition shows a consistent change in PPR (facilitation to depression: PPF to PPD). (C) Time course of LTP induction (same cell as in B). (Open circles) Individual responses, (filled gray circles) averages of 10 individual responses. $(D)$ Amplitude normalization and average of eight experiments similar to that in $B, C$. (E) Histogram illustrating normalized IPSCs amplitudes before and after HFS ( $\left.{ }^{\star} P<0.001 ; n=8\right)$. ( $\left.F\right)$ Statistically significant PPR changes in the cell sample $\left({ }^{*} P<0.03 ; n=8\right)$. (Filled circles) Individual experiments, (open circles) mean of individual experiments. 
element at these synapses, as is the case for their glutamatergic counterparts (Calabresi et al. 1992b).

In addition, LTP accompanied by a significant and consistent change of PPR was found at strionigral synapses, suggesting a presynaptic mechanism (Zucker 1989; Choi and Lovinger 1997). The interest of these findings resides in that basal ganglia main circuits are divided into "direct" and "indirect" pathways with precise hypothetical roles and tasks (DeLong and Wichmann 2007), and, more importantly, with heterogeneous synaptic processing within and in between the neurons of these pathways (Taverna et al. 2008). Heterogeneity of synaptic processing with the same class of cells in the presynaptic side but different postsynaptic targets has been described (e.g., Markram et al. 1998).

Thus, a question arises about the significance of the physiological division found in the present study. According to the classical model of the basal ganglia circuitry (Alexander et al. 1986; Albin et al. 1989), simultaneous LTP and LTD on strionigral and striopallidal pathways, respectively, is expected to produce synergistic actions at the system level (Silkis 2001) during learning of motor procedures. A direct pathway enhancement would promote movement by disinhibiting thalamocortical circuits influencing premotor and motor cortices, while a reduced inhibition on external GP would lead to an increased inhibition of the subthalamic nucleus (STN), which in turn reduces the excitatory tone to the output nuclei and therefore thalamocortical inhibition. Thus, procedural learning would in theory be facilitated by these simultaneous and synergistic plastic changes. Therefore, it is perhaps not surprising to find the right type of long-term synaptic plasticity in the right synapses.

Facilitation of learned motor behaviors would correlate with synaptic weight changes at corticobasal loops during the acquisition of procedures. Moreover, these plasticities go along with known actions of both $\mathrm{D}_{1}$ - and $\mathrm{D}_{2}$-class dopamine receptors on direct and indirect striatal pathway neurons, respectively (Hernández-López et al. 1997, 2000). To our knowledge, this is the first report of longterm synaptic plasticity at inhibitory synapses in the GP and SNr. On the other hand, a previous report has shown synaptic plasticity at inhibitory synapses within the NSt (Adermark et al. 2009).

\section{Acknowledgments}

This work was supported by IMPULSA (UNAM) 03, DGAPA (UNAM) grants IN 201603 to J.B., IN-201507 to E.G., and CONACYTMexico Grant 49484 to J.B. P.E.R.-O. is currently a postdoctoral fellow at UNAM. E.M., R.H., J.J.A., and O.I.-S. have or had CONACyT-Mexico doctoral fellowships.

\section{References}

Adermark L, Talani G, Lovinger DM. 2009. Endocannabinoid-dependent plasticity at GABAergic and glutamatergic synapses in the striatum is regulated by synaptic activity. Eur J Neurosci 29: 32-41.

Albin RL, Young AB, Penney JB. 1989. The functional anatomy of basal ganglia disorders. Trends Neurosci 12: 366-375.

Alexander GE, DeLong MR, Strick PL. 1986. Parallel organization of functionally segregated circuits linking basal ganglia and cortex. Annu Rev Neurosci 9: 357-381.

Beurrier C, Ben-Ari Y, Hammond C. 2006. Preservation of the direct and indirect pathways in an in vitro preparation of the mouse basal ganglia. Neuroscience 140: $77-86$.

Bliss TV, Lomo T. 1973. Long-lasting potentiation of synaptic transmission in the dentate area of the anaesthetized rabbit following stimulation of the perforant path. J Physiol 232: 331-356.

Calabresi P, Maj R, Pisani A, Mercuri NB, Bernardi G. 1992a. Long-term synaptic depression in the striatum: Physiological and pharmacological characterization. I Neurosci 11: 4224-4233.

Calabresi P, Pisani A, Mercuri NB, Bernardi G. 1992b. Long-term potentiation in the striatum is unmasked by removing the voltagedependent magnesium block of NMDA receptor channels. Eur J Neurosci 4: $929-935$.
Carrillo-Reid L, Tecuapetla F, Tapia D, Hernández-Cruz A, Galarraga E, Drucker-Colin R, Bargas J. 2008. Encoding network states by striatal cell assemblies. J Neurophysiol 99: 1435-1450.

Carrillo-Reid L, Tecuapetla F, Ibáñez-Sandoval O, Hernández-Cruz A, Galarraga E, Bargas J. 2009. Activation of the cholinergic system endows compositional properties to striatal cell assemblies. J Neurophysiol 101: 737-749.

Castro-Alamancos MA, Donoghue JP, Connors BW. 1995. Different forms of synaptic plasticity in somatosensory and motor areas of the neocortex. $J$ Neurosci 15: 5324-5333.

Charpier S, Deniau JM. 1997. In vivo activity-dependent plasticity at corticostriatal connections: Evidence for physiological long-term potentiation. Proc Natl Acad Sci 94: 7036-7040.

Chevaleyre V, Castillo PE. 2003. Heterosynaptic LTD of hippocampal GABAergic synapses: A novel role of endocannabinoids in regulating excitability. Neuron 38: 461-472.

Choi S, Lovinger DM. 1997. Decreased probability of neurotransmitter release underlies striatal long-term depression and postnatal development of corticostriatal synapses. Proc Natl Acad Sci 18: 26652670.

Cools AR. 1984. Basal ganglia and Parkinson's disease: Neurobiological and pharmacological aspects in animals and man. Clin Neurol Neurosurg 86: 178-195.

Cooper AJ, Stanford IM. 2001. Dopamine D2 receptor mediated presynaptic inhibition of striatopallidal $\mathrm{GABA}_{\mathrm{A}}$ IPSCs in vitro. Neuropharmacol 41: 62-71.

DeLong MR, Wichmann T. 2007. Circuits and circuit disorders of the basal ganglia. Arch Neurol 64: 20-24.

Dudek SM, Bear MF. 1992. Homosynaptic long-term depression in area CA1 of hippocampus and effects of $N$-methyl-D-aspartate receptor blockade. Proc Natl Acad Sci 89: 4363-4367.

Engler B, Freiman I, Urbanski M, Szabo B. 2006. Effects of exogenous and endogenous cannabinoids on GABAergic neurotransmission between the caudate-putamen and the globus pallidus in the mouse. J Pharmacol Exp Ther 316: 608-617.

Flores-Barrera E, Laville A, Plata V, Tapia D, Bargas J, Galarraga E. 2009. Inhibitory contribution to suprathreshold corticostriatal responses: An experimental and modeling study. Cell Mol Neurobiol 29: 719-731.

Graybiel AM. 2008. Habits, rituals, and the evaluative brain. Annu Rev Neurosci 31: 356-387.

Guzmán JN, Hernández A, Galarraga E, Tapia D, Laville A, Vergara R, Aceves J, Bargas J. 2003. Dopaminergic modulation of axon collaterals interconnecting spiny neurons of the rat striatum. J Neurosci 23: 89318940.

Hernández-López S, Bargas J, Surmeier DJ, Reyes A, Galarraga E. 1997. D receptor activation enhances evoked discharge in neostriatal medium spiny neurons by modulating an L-type $\mathrm{Ca}^{2+}$ conductance. J Neurosci 17: 3334-3342.

Hernández-López S, Tkatch T, Perez-Garci E, Galarraga E, Bargas J, Hamm H, Surmeier DJ. 2000. $\mathrm{D}_{2}$ dopamine receptors in striatal medium spiny neurons reduce L-type $\mathrm{Ca}^{2+}$ currents and excitability via a novel PLC $\beta 1-I_{3}$-calcineurin-signaling cascade. J Neurosci 20: 8987-8995.

Kano M. 1995. Plasticity of inhibitory synapses in the brain: A possible memory mechanism that has been overlooked. Neurosci Res 21: 177182.

Lemus-Aguilar I, Bargas J, Tecuapetla F, Galarraga E, Carrillo-Reid L. 2006. Diseño modular de instrumentación virtual para la manipulación y el análisis de señales eletrotisiológicas. Rev Mex Ing Biomed 27: 82-92.

Lovinger DM, Tyler EC, Merrit A. 1993. Short- and long-term synaptic depression in rat neostriatum. J Neurophysiol 70: 1937-1949.

Malenka RC, Bear MF. 2004. LTP and LTD: An embarrassment of riches. Neuron 44: 5-21.

Markram H, Wang Y, Tsodyks M. 1998. Differential signaling via the same axon of neocortical pyramidal neurons. Proc Natl Acad Sci 95: 53235328.

Martin SJ, Grimwood PD, Morris RG. 2000. Synaptic plasticity and memory: An evaluation of the hypothesis. Annu Rev Neurosci 23: 649711.

Mendoza E, Galarraga E, Tapia D, Laville A, Hernandez-Echeagaray E, Bargas J. 2006. Differential induction of long term synaptic plasticity in inhibitory synapses of the hippocampus. Synapse 60: 533-542.

Misgeld U, Drew G, Yanovsky Y. 2007. Presynaptic modulation of GABA release in the basal ganglia. Prog Brain Res 160: 245-259.

Perez-Rosello T, Figueroa A, Salgado H, Vilchis C, Tecuapetla F, Guzmán JN Galárraga E, Bargas J. 2005. Colinergic control of firing pattern and neurotransmission in rat neostriatal projection neurons: Role of $\mathrm{Ca}_{\mathrm{V}} 2.1$ and $\mathrm{Ca}_{\mathrm{V}} 2.2 \mathrm{Ca}^{2+}$ channels. J Neurophysiol 93: 2507-2519.

Racine RJ, Milgram NW, Hafner S. 1983. Long-term potentiation phenomena in the rat limbic forebrain. Brain Res 260: 217-231.

Radnikow G, Misgeld U. 1998. Dopamine $D_{1}$ receptors facilitate $G_{A B A}$ synaptic currents in the rat substantia nigra pars reticulata. J Neurosci 18: 2009-2016. 
Salgado H, Tecuapetla F, Perez-Rosello T, Perez-Burgos A, Perez-Garci E, Galárraga E, Bargas J. 2005. A reconfiguration of $\mathrm{Ca}_{\mathrm{V}} 2 \mathrm{Ca}^{2+}$ channel current and its dopaminergic $\mathrm{D}_{2}$ modulation in developing neostriatal neurons. J Neurophysiol 94: 3771-3787.

Shen W, Flajolet M, Greengard P, Surmeier DJ. 2008. Dichotomous dopaminergic control of striatal synaptic plasticity. Science $\mathbf{3 2 1}$ : 848-851.

Shin RM, Masuda M, Miura M, Sano H, Shirasawa T, Song WJ, Kobayashi K, Aosaki T. 2003. Dopamine $\mathrm{D}_{4}$ receptor-induced postsynaptic inhibition of GABAergic currents in mouse globus pallidus neurons. J Neurosci 23: 11662-11672.

Silkis I. 2001. The cortico-basal ganglia-thalamocortical circuit with synaptic plasticity. II. Mechanism of synergistic modulation of thalamic activity via the direct and indirect pathways through the basal ganglia. Biosystems 59: 7-14.

Sims RE, Woodhall CL, Wilson CL, Stanford IM. 2008. Functional characterization of GABAergic pallidopallidal and striatopallidal synapses in the rat globus pallidus. Eur J Neurosci 28: 2401-2408.

Sjostrom PJ, Rancz EA, Roth A, Hausser M. 2008. Dendritic excitability and synaptic plasticity. Physiol Rev 88: 769-840.
Taverna S, Ilijic E, Surmeier DJ. 2008. Recurrent collateral connections of striatal medium spiny neurons are disrupted in models of Parkinson's disease. J Neurosci 28: 5504-5512.

Tecuapetla F, Carrillo-Reid L, Guzmán JN, Galarraga E, Bargas J. 2005 Different inhibitory inputs onto neostriatal projection neurons as revealed by field stimulation. J Neurophysiol 93: 1119-1126.

Tecuapetla F, Carrillo-Reid L, Bargas J, Galarraga E. 2007. Dopaminergic modulation of short-term synaptic plasticity at striatal inhibitory synapses. Proc Natl Acad Sci 104: 10258-10263.

Wang SJ, Gean PW. 1999. Long-term depression of excitatory synaptic transmission in the rat amygdala. J Neurosci 19: 10656-10663.

Yin HH, Mulcare SP, Hilário MR, Clouse E, Holloway T, Davis MI, Hansson AC, Lovinger DM, Costa RM. 2009. Dynamic reorganization of striatal circuits during the acquisition and consolidation of a skill. Nat Neurosci 12: $333-341$.

Zucker RS. 1989. Short-term synaptic plasticity. Annu Rev Neurosci 12: 13-31.

Received March 31, 2009; accepted in revised form June 5, 2009. 


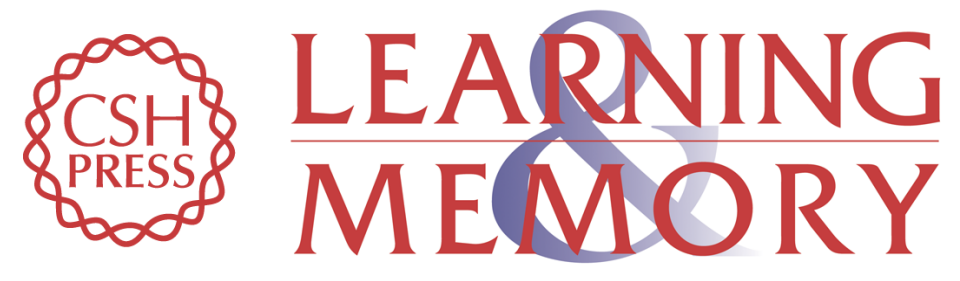

\section{Diversity in long-term synaptic plasticity at inhibitory synapses of striatal spiny neurons}

Pavel E. Rueda-Orozco, Ernesto Mendoza, Ricardo Hernandez, et al.

Learn. Mem. 2009, 16:

Access the most recent version at doi:10.1101//m.1439909

Supplemental
Material http://learnmem.cshlp.org/content/suppl/2009/08/03/16.8.474.DC1

References This article cites 46 articles, 14 of which can be accessed free at: http://learnmem.cshlp.org/content/16/8/474.full.html\#ref-list-1

License

Email Alerting Receive free email alerts when new articles cite this article - sign up in the box at the Service top right corner of the article or click here. 